\title{
Clinicopathological characteristics and outcomes in stage I-III mucinous gastric adenocarcinoma: a retrospective study at a single medical center
}

\author{
Jun-Te Hsu' ${ }^{1 *}$, Chen-Wei Wang ${ }^{1}$, Puo-Hsien Le ${ }^{2}$, Ren-Chin Wu ${ }^{3}$, Tsung-Hsing Chen ${ }^{2}$, Kun-Chun Chiang ${ }^{4}$, \\ Chun-Jung Lin $^{2}$ and Ta-Sen Yeh ${ }^{1}$
}

\begin{abstract}
Background: The clinicopathological characteristics and outcomes of mucinous gastric adenocarcinoma (GC) remain unclear. We report the clinicopathological features and prognosis of patients with mucinous histology who underwent radical-intent gastrectomy.

Methods: We reviewed the medical records of 1470 patients with pathologically proven undifferentiated GC undergoing radical-intent gastrectomy between 1995 and 2007. The patients were stratified into three groups according to their histological type: mucinous carcinoma (MC), signet ring cell carcinoma (SRCC), and poorly differentiated carcinoma (PDC). Clinicopathological factors affecting prognosis were collected prospectively and analyzed.

Results: In stage III MC, the age and size were significantly greater and larger than in SRCC and PDC; a lower proportion of perineural invasion was identified in MC, and female predominance was noted in SRCC in comparison with MC and PDC. The cumulative overall survival rates of stage I-III GC patients with MC were significantly superior compared to those with PDC, but not SRCC. Stage III GC patients with MC had a better prognosis than those with SRCC or PDC; the difference in survival was not evident in stages I or II.
\end{abstract}

Conclusions: Thus, MC presents with different clinicopathological features and prognosis from SRCC and PDC. The patients with stage III gastric MC had favorable outcomes.

Keywords: Mucinous gastric cancer, Undifferentiated, Prognostic factor

\section{Background}

Despite the decreasing overall worldwide incidence of gastric adenocarcinoma (GC), GC has remained the third leading cause of cancer-related death, after lung and liver malignancies, leading to around 723,000 deaths in 2012 [1]. Most GC patients present with locally advanced or metastatic disease, and radical surgical resection is still the mainstay of treatment for localized disease $[2,3]$. According to the Japanese classification for histological typing for $\mathrm{GC}$, mucinous carcinoma

\footnotetext{
* Correspondence: hsujt2813@adm.cgmh.org.tw

'Department of General Surgery, Chang Gung Memorial Hospital at Linkou, Chang Gung University College of Medicine, 5, Fushing Street, Kweishan District, Taoyuan City 333, Taiwan

Full list of author information is available at the end of the article
}

(MC) or signet ring cell carcinoma (SRCC) is defined as the undifferentiated type [4]. Undifferentiated carcinoma also has different biological behaviors than differentiated carcinoma, such as the growth pattern, invasiveness, metastasis, and prognosis [5]. However, even between tumors belonging to the undifferentiated histology subtype, there can be significant heterogeneity in terms of tumor biology and prognosis. Studies reported that MC accounts for $2.6-7.6 \%$ of all GC [6]. Only a few studies on gastric MC have been reported, and its clinicopathological features and prognosis were inconsistent [5-7]. For example, Yin et al. indicated that there was no difference in survival between $\mathrm{MC}$ and non-MC [6]. However, Kunisaki et al. observed that MC had a poor prognosis compared with non-MC [7]. The aims of this 
Table 1 Clinicopathological characteristics of stage I-III undifferentiated gastric adenocarcinoma in terms of histology type

\begin{tabular}{|c|c|c|c|c|}
\hline Parameters & $M C(n=54)$ & $\operatorname{SRCC}(n=545)$ & $\operatorname{PDC}(n=871)$ & $P$ value \\
\hline Age (years), mean $\pm S D$ & $64.2 \pm 10.7$ & $58.4 \pm 13.4$ & $62.5 \pm 13.8$ & $<0.0001$ \\
\hline Median & 66.0 & 59.0 & 65.0 & \\
\hline Sex & & & & $<0.001$ \\
\hline Male & $31(57.4)$ & $269(49.4)$ & $522(59.9)$ & \\
\hline Female & $23(42.6)$ & $276(50.6)$ & $349(40.1)$ & \\
\hline Tumor size $(\mathrm{cm})$, mean $\pm \mathrm{SD}$ & $6.4 \pm 3.9$ & $4.3 \pm 3.4$ & $5.1 \pm 3.2$ & $<0.0001$ \\
\hline Median & 5.5 & 3.5 & 4.5 & \\
\hline Type of gastrectomy & & & & 0.006 \\
\hline Total & $16(29.6)$ & $133(24.4)$ & $282(32.4)$ & \\
\hline Subtotal & $38(70.4)$ & $412(75.6)$ & $589(67.6)$ & \\
\hline Extent of LN dissection & & & & 0.773 \\
\hline$<\mathrm{D} 2$ & $21(38.9)$ & $187(34.3)$ & $308(35.4)$ & \\
\hline$\geq \mathrm{D} 2$ & $33(61.1)$ & $358(65.7)$ & $563(64.6)$ & \\
\hline No. of $\mathrm{LN}$ retrieval, mean $\pm \mathrm{SD}$ & $27.3 \pm 15.8$ & $28.1 \pm 15.3$ & $27.7 \pm 14.7$ & 0.856 \\
\hline Median & 23.0 & 25.0 & 25.0 & \\
\hline T status & & & & $<0.0001$ \\
\hline $\mathrm{T} 1$ & $2(3.7)$ & $163(29.9)$ & $101(11.6)$ & \\
\hline $\mathrm{T} 2$ & $9(16.7)$ & $56(10.3)$ & $74(8.5)$ & \\
\hline T3 & $3(5.6)$ & $19(3.5)$ & $24(2.8)$ & \\
\hline $\mathrm{T} 4$ & $40(74.1)$ & $307(56.3)$ & $672(77.2)$ & \\
\hline \multicolumn{5}{|l|}{ LN status } \\
\hline NO & $13(24.1)$ & $251(46.1)$ & $244(28.0)$ & $<0.0001$ \\
\hline N1 & $11(20.4)$ & $59(10.8)$ & $119(13.7)$ & \\
\hline N2 & $12(22.2)$ & $66(12.1)$ & $56(17.9)$ & \\
\hline N3 & $18(33.3)$ & $169(31.0)$ & $352(40.4)$ & \\
\hline Stage & & & & $<0.0001$ \\
\hline । & $5(9.3)$ & $190(34.9)$ & $120(13.8)$ & \\
\hline$\|$ & $10(18.5)$ & $94(17.2)$ & $170(19.5)$ & \\
\hline III & $39(72.2)$ & $261(47.9)$ & $581(66.7)$ & \\
\hline Positive margins (R1 resection) & $8(14.8)$ & $59(10.8)$ & $95(10.9)$ & 0.662 \\
\hline Lymphatic invasion $^{a}$ & & & & $<0.0001$ \\
\hline No & $21(39.6)$ & $288(53.4)$ & $315(36.7)$ & \\
\hline Yes & $32(60.4)$ & $251(46.6)$ & $544(63.3)$ & \\
\hline Vascular invasion ${ }^{a}$ & & & & 0.005 \\
\hline No & $44(83.0)$ & $479(89.2)$ & $710(82.9)$ & \\
\hline Yes & $9(17.0)$ & $58(10.8)$ & $146(17.1)$ & \\
\hline Perineural invasion ${ }^{\mathrm{a}}$ & & & & 0.001 \\
\hline No & $27(51.9)$ & $294(54.9)$ & $380(44.3)$ & \\
\hline Yes & $25(48.1)$ & $242(45.1)$ & $477(55.7)$ & \\
\hline Complications $^{\mathrm{b}}$ & $12(22.2)$ & $61(11.2)$ & $136(15.6)$ & 0.016 \\
\hline Surgery-related & $10(18.5)$ & $49(9.0)$ & $99(11.4)$ & 0.064 \\
\hline Leakage & $5(9.3)$ & $26(4.8)$ & $46(5.3)$ & \\
\hline Intra-abdominal abscess & $4(7.4)$ & $18(3.3)$ & $38(4.4)$ & \\
\hline Wound infection & $1(1.9)$ & $5(0.9)$ & $22(2.5)$ & \\
\hline
\end{tabular}


Table 1 Clinicopathological characteristics of stage I-III undifferentiated gastric adenocarcinoma in terms of histology type (Continued)

\begin{tabular}{llll}
\hline Bleeding & $1(1.9)$ & $9(1.7)$ & $11(1.3)$ \\
Delayed gastric emptying & 0 & $1(0.2)$ & $6(0.7)$ \\
Others & $1(1.9)$ & $3(0.6)$ & $4(0.5)$ \\
Surgery unrelated & $3(5.6)$ & $19(3.5)$ & $59(6.8)$ \\
Pneumonia & $1(1.9)$ & $2(0.4)$ & $15(1.7)$ \\
Cardiovascular event & $1(1.9)$ & $5(0.9)$ & $7(0.8)$ \\
Sepsis & 0 & $2(0.4)$ & $8(0.9)$ \\
Paralytic ileus & 0 & $2(0.4)$ & $5(0.6)$ \\
Atelectasis & 0 & 0 & $6(0.7)$ \\
Others & $4(7.4)$ & $21(3.9)$ & $45(5.2)$ \\
Hospital mortality & $4(7.4)$ & $14(2.6)$ & $33(3.8)$ \\
Chemotherapyc & $38(84.4)$ & $285(81.7)$ & $553(75.6)$ \\
\hline
\end{tabular}

Figures are numbers with percentages in parentheses, unless otherwise stated

LN lymph node, MC mucinous carcinoma, PDC poorly differentiated carcinoma, SD standard deviation, SRCC signet ring cell carcinoma

${ }^{\text {a }}$ Some data were missing

${ }^{\mathrm{b}}$ Number of patients with event

${ }^{\mathrm{C}}$ Excluding $\mathrm{T} 1 / \mathrm{T} 2 \mathrm{~N} 0$ cases or hospital mortality

study were to elucidate the clinicopathological characteristics and to clarify the prognosis of stage I-III resected GC patients with $\mathrm{MC}$ compared with other undifferentiated subtypes.

\section{Methods}

\section{Ethics statement}

The study protocol was approved by the Institutional Review Board of Chang Gung Memorial Hospital (No. 100-4279B). Written informed consent was obtained from all the patients. All data were stored in the hospital database and used for research.

\section{Patients and surgical procedures}

We reviewed the medical records of 1470 patients with pathologically proven undifferentiated GC undergoing radical-intent gastrectomy at Chang Gung Memorial Hospital, Taoyuan, Taiwan, between 1995 and 2007; patients with a history of partial gastrectomies were excluded. The patients were stratified into three groups according to the histological types: MC, SRCC, and poorly differentiated carcinoma (PDC). Subtotal or total gastrectomy was performed according to the tumor size, location of tumor, and status of resection margins. The standard procedure included a spleen- and pancreaspreserving D1 or D2 lymph node dissection, depending on the perceived extent of tumor invasion and lymph node metastasis [2]. Resection of adjacent organs was undertaken to achieve clear margins when deemed necessary [8]. Surgery-related complications included anastomotic/duodenal stump leakage, wound infection, intra-abdominal abscess/bleeding, and delayed gastric emptying, while pneumonia, cardiovascular event, atelectasis, sepsis, paralytic ileus, pleural effusion, urinary retention, and psychoneurologic event were considered as surgery-unrelated complications. Lymphatic, vascular, or perineural invasion was defined as the presence of permeation of the tumor in the lymphatic duct, vascular structure, or nerve microscopically, respectively. The tumors were staged according to the seventh edition of the American Joint Committee on Cancer Tumor Node Metastasis classification [9]. Postoperative adjuvant chemotherapy with fluoropyrimidine-based or platinumbased regimens was indicated for patients with stage II-III disease, while patients with stage IB did not routinely received adjuvant chemotherapy except for those with tumors showing poor differentiation or lymphatic, vascular, or perineural invasion. No patient received neoadjuvant chemotherapy. The median follow-up time was 41.0 months, ranging from 1.2 to 215.9 months. The patients who died after surgery during the same hospitalization were defined as hospital mortality and were not included in the long-term survival analysis. Survival duration was calculated from the time of surgery to death or the last follow-up date (December 31, 2012), irrespective of the cause of death.

\section{Statistical analysis}

Clinical records were compared with either Fischer's exact test or Pearson's $\chi^{2}$ test, as appropriate. The patient survival rate was calculated using the Kaplan-Meier curve, and univariate analysis was conducted using the log-rank test. Factors that were deemed of potential importance to the univariate analysis $(P<0.05)$ were included in the multivariate analysis using the Cox regression model. $P<0.05$ was considered significant. Statistical analyses 
Table 2 Clinicopathological characteristics of stage III undifferentiated gastric adenocarcinoma in terms of histology type

\begin{tabular}{|c|c|c|c|c|}
\hline Parameters & $\mathrm{MC}(n=39)$ & $\operatorname{SRCC}(n=261)$ & $\operatorname{PDC}(n=581)$ & $P$ value \\
\hline Age (years), mean $\pm S D$ & $64.5 \pm 10.0$ & $60.2 \pm 13.7$ & $62.7 \pm 14.0$ & 0.019 \\
\hline Median & 66.0 & 61.0 & 66.0 & \\
\hline Sex & & & & 0.002 \\
\hline Male & $22(56.4)$ & $128(49.0)$ & $359(61.8)$ & \\
\hline Female & $17(43.6)$ & $133(51.0)$ & $222(38.2)$ & \\
\hline Tumor size $(\mathrm{cm})$, mean $\pm \mathrm{SD}$ & $7.6 \pm 3.9$ & $6.0 \pm 3.7$ & $5.8 \pm 3.1$ & 0.006 \\
\hline Median & 7.0 & 5.0 & 5.0 & \\
\hline Type of gastrectomy & & & & 0.696 \\
\hline Total & $13(33.3)$ & $96(36.8)$ & $226(38.9)$ & \\
\hline Subtotal & $26(66.7)$ & $165(63.2)$ & $355(61.1)$ & \\
\hline Extent of LN dissection & & & & 0.268 \\
\hline$<\mathrm{D} 2$ & $13(33.3)$ & $71(27.2)$ & $190(32.7)$ & \\
\hline$\geq \mathrm{D} 2$ & $26(66.7)$ & $190(72.8)$ & $391(67.3)$ & \\
\hline No. of $L N$ retrieval, mean $\pm S D$ & $29.2 \pm 16.3$ & $30.2 \pm 16.2$ & $28.6 \pm 14.9$ & 0.373 \\
\hline Median & 25.0 & 27.0 & 26.0 & \\
\hline T status & & & & 0.627 \\
\hline $\mathrm{T} 2$ & $2(5.1)$ & $6(2.3)$ & $10(1.7)$ & \\
\hline T3 & $1(2.6)$ & $5(1.9)$ & $9(1.5)$ & \\
\hline $\mathrm{T} 4$ & $36(92.3)$ & $250(95.8)$ & $562(96.8)$ & \\
\hline \multicolumn{5}{|l|}{ LN status } \\
\hline NO & $2(5.1)$ & $1(0.4)$ & $13(2.2)$ & 0.118 \\
\hline N1 & $8(20.5)$ & $41(15.7)$ & $86(14.8)$ & \\
\hline N2 & $11(28.2)$ & $52(19.9)$ & $136(23.4)$ & \\
\hline N3 & $18(46.2)$ & $167(64.0)$ & $346(59.6)$ & \\
\hline Positive margins (R1 resection) & $8(20.5)$ & $48(18.4)$ & $84(14.5)$ & 0.255 \\
\hline Lymphatic invasion $^{\mathrm{a}}$ & & & & 0.442 \\
\hline No & $8(21.1)$ & $35(13.5)$ & $88(15.4)$ & \\
\hline Yes & $30(78.9)$ & $225(86.5)$ & $484(84.6)$ & \\
\hline Vascular invasion ${ }^{a}$ & & & & 0.767 \\
\hline No & $30(78.9)$ & $204(79.1)$ & $439(76.9)$ & \\
\hline Yes & $8(21.1)$ & $54(20.9)$ & $132(23.1)$ & \\
\hline Perineural invasion ${ }^{a}$ & & & & 0.003 \\
\hline No & $17(45.9)$ & $57(22.2)$ & $175(30.8)$ & \\
\hline Yes & $20(54.1)$ & $200(77.8)$ & $394(69.2)$ & \\
\hline Complications $^{\mathrm{b}}$ & $8(20.5)$ & $44(16.9)$ & $101(17.4)$ & 0.854 \\
\hline Surgery-related & $8(20.5)$ & $35(13.4)$ & $71(12.2)$ & 0.316 \\
\hline Leakage & $4(10.3)$ & $19(7.3)$ & $34(5.9)$ & \\
\hline Intra-abdominal abscess & $4(10.3)$ & $12(4.6)$ & $28(4.8)$ & \\
\hline Wound infection & $1(2.6)$ & $4(1.5)$ & $15(2.6)$ & \\
\hline Bleeding & $1(2.6)$ & $8(3.1)$ & $9(1.5)$ & \\
\hline Delayed gastric emptying & 0 & $1(0.4)$ & $4(0.7)$ & \\
\hline Others & 0 & $3(1.1)$ & $3(0.5)$ & \\
\hline Surgery unrelated & $1(2.6)$ & $16(6.1)$ & $48(8.3)$ & 0.275 \\
\hline Pneumonia & 0 & $2(0.8)$ & $12(2.1)$ & \\
\hline
\end{tabular}


Table 2 Clinicopathological characteristics of stage III undifferentiated gastric adenocarcinoma in terms of histology type (Continued)

\begin{tabular}{llll}
\hline Cardiovascular event & 0 & $5(1.9)$ & $6(1.0)$ \\
Sepsis & 0 & $2(0.8)$ & $7(1.2)$ \\
Paralytic ileus & 0 & $1(0.4)$ & $4(0.7)$ \\
Atelectasis & 0 & 0 & $5(0.9)$ \\
Others & $1(2.6)$ & $18(6.9)$ & $38(6.5)$ \\
Hospital mortality & $2(5.1)$ & $13(5.0)$ & $32(5.5)$ \\
Chemotherapy & $30(76.9)$ & $205(78.5)$ & $423(72.8)$ \\
\hline
\end{tabular}

Figures are numbers with percentages in parentheses, unless otherwise stated

$L N$ lymph node, $M C$ mucinous carcinoma, SD standard deviation, PDC poorly differentiated carcinoma, SRCC signet ring cell carcinoma

${ }^{\mathrm{a} S o m e}$ data were missing

${ }^{b}$ Number of patients with event

were performed with SPSS software for Windows, version 13 (SPSS, Inc., Chicago, IL, USA).

\section{Results}

\section{Demographics and clinicopathological data}

Table 1 shows the demographics and clinicopathological features of patients with stage I-III undifferentiated GC who underwent potentially curative gastrectomy stratified according to histology type. No difference was noted in terms of the extent of lymphadenectomy, number of lymph nodes retrieved, resection margins, surgeryrelated complications, and hospital mortality among the three groups. Older patients $(P<0.0001)$, larger tumor size $(P<0.0001)$, higher incidences of stage III tumors $(P<0.001)$, higher total complication rates $(P=$ 0.016 ), and higher percentages of patients receiving adjuvant chemotherapy $(P=0.047)$ were observed in the group of patients with $\mathrm{MC}$ histology than in those with the SRCC or PDC subtypes. Compared with MC and PDC, SRCC had female predominance $(P<0.001)$; higher incidences of T4 tumors $(P<0.0001)$; and greater lymphatic $(P<0.0001)$, vascular $(P=0.005)$, or perineural $(P=0.001)$ invasion. More total gastrectomy procedures $(P=0.006)$, cases with N3 status $(P<0.0001)$, and surgery-unrelated complications $(P=0.031)$ were noted in the PDC subtype than in SRCC and MC. In stage III undifferentiated GC patients, MC had older patients $(P=$ $0.019)$, larger tumor size $(P=0.006)$, and more perineural $(P=0.003)$ invasion than SCC and PDC (Table 2).

\section{Analysis of prognostic factors}

Univariate analysis indicated that the type of gastrectomy; ratio of metastatic to examined lymph nodes; nodal status; histology type; resection margins; presence of lymphatic, vascular, and perineural invasion; and patients receiving adjuvant chemotherapy were significant prognostic factors for stage III undifferentiated GC patients (Table 3). Multivariate analysis showed that the following factors significantly affected survival in stage III undifferentiated GC patients: type of gastrectomy (total vs. subtotal; hazard ratio $(\mathrm{HR})=1.130 ; P=0.001$ ), tumor size ( $>5 \mathrm{~cm}$ vs. $\leq \mathrm{cm}$; HR $=1.251 ; P=0.013)$, ratio of metastatic to examined lymph nodes $(>0.34 \mathrm{~cm}$ vs. $\leq 0.34 \mathrm{~cm} ; \mathrm{HR}=1.892 ; P<0.0001)$, positive resection margins $(\mathrm{HR}=1.238 ; P<0.001)$, histology type (PDC vs. $\mathrm{MC} ; \mathrm{HR}=1.594 ; P=0.04)$, the presence of perineural invasion ( $\mathrm{HR}=1.335 ; P=0.004)$, and no administration of chemotherapy $(\mathrm{HR}=1.381 ; P=0.002)$ (Table 4$)$.

\section{Cumulative survival rates}

The 5-year overall survival (OS) rates of stage I-III undifferentiated GC patients undergoing potentially curative resection were 58.8, 59.2, and $45.1 \%$ in SRCC, MC, and PDC, respectively (Fig. $1 ; P<0.0001$ ). Similar OS rates were found for stage I (Fig. $2 \mathrm{a} ; P=0.399$ ) and stage II (Fig. 2b; $P<0.274$ ) patients in the three groups. Compared to stage III SRCC and PDC patients, MC patients had markedly favorable OS rates (Fig. 2c; $P=0.038$ ).

\section{Discussion}

In accordance with previous reports $[6,10], \mathrm{MC}$ of the stomach is a rare histologic type of GC, comprising $4.4 \%$ of the cases of undifferentiated stage I-III GC in our study. In potentially curative resected GC (stages IIII), MC patients were older than SRCC or PDC patients and the tumors in $\mathrm{MC}$ patients were larger than those in SRCC or PDC patients. Patients with MC were more often diagnosed as stage III compared with the other undifferentiated subtypes. In stage III GC, the age and size of MC were significantly older and larger than SRCC or PDC, respectively; lower proportions of perineural invasion were identified in $\mathrm{MC}$, and female predominance was noted in SRCC in comparison with the other two subtypes. The cumulative OS rates of stage I-III GC patients with $\mathrm{MC}$ were significantly longer compared to those with PDC, but not SRCC. Stage III GC patients with MC had a better prognosis than those with SRCC or PDC; the difference in survival was not evident in stage I or II patients. 
Table 3 Univariate analysis of prognostic factors for stage III undifferentiated gastric adenocarcinoma

\begin{tabular}{|c|c|c|c|c|c|}
\hline Factors & Median survival (months) & $95 \% \mathrm{Cl}$ for median & 3-year survival (\%) & 5-year survival (\%) & $P$ value \\
\hline Age (years) & & & & & 0.200 \\
\hline$\leq 65(n=449)$ & 23.8 & $20.4-27.3$ & 39.2 & 29.2 & \\
\hline$>65(n=385)$ & 21.8 & $19.0-24.6$ & 33.5 & 24.1 & \\
\hline Sex & & & & & 0.374 \\
\hline Male $(n=474)$ & 21.8 & $19.1-24.6$ & 34.7 & 25.8 & \\
\hline Female $(n=360)$ & 25.2 & $21.3-29.2$ & 38.3 & 28.6 & \\
\hline Tumor size $(\mathrm{cm})$ & & & & & 0.223 \\
\hline$\leq 5(n=410)$ & 28.4 & $23.9-33.0$ & 43.1 & 32.9 & \\
\hline$>5(n=420)$ & 19.0 & $16.6-21.4$ & 29.2 & 21.6 & \\
\hline Type of gastrectomy & & & & & $<0.0001$ \\
\hline Total $(n=308)$ & 17.8 & 15.0-20.7 & 29.6 & 20.6 & \\
\hline Subtotal $(n=526)$ & 26.6 & $23.1-30.1$ & 40.1 & 30.7 & \\
\hline Extent of LN dissection & & & & & 0.834 \\
\hline$<\mathrm{D} 2(n=246)$ & 24.3 & $19.6-28.9$ & 36.2 & 27.3 & \\
\hline$\geq \mathrm{D} 2(n=588)$ & 22.2 & $19.3-25.2$ & 36.2 & 26.9 & \\
\hline T status & & & & & 0.817 \\
\hline $\mathrm{T} 1 / \mathrm{T} 2(n=17)$ & 17.6 & $5.6-9.6$ & 41.2 & 32.9 & \\
\hline $\mathrm{T} 3 / \mathrm{T} 4(n=817)$ & 23.0 & $20.5-25.6$ & 36.2 & 26.9 & \\
\hline LN ratio & & & & & $<0.0001$ \\
\hline$\leq 0.34(n=416)$ & 38.7 & $30.8-46.7$ & 52.4 & 41.9 & \\
\hline$>0.34(n=418)$ & 15.8 & $13.5-18.1$ & 20.1 & 12.0 & \\
\hline N status & & & & & $<0.0001$ \\
\hline No $(n=15)$ & NA & & 57.8 & 57.8 & \\
\hline N1 $(n=129)$ & 65.3 & $29.5-101.1$ & 58.9 & 50.3 & \\
\hline N2 $(n=188)$ & 28.6 & $20.1-37.1$ & 44.3 & 33.8 & \\
\hline N3 $(n=52)$ & 18.8 & $16.7-0.9$ & 26.5 & 17.3 & \\
\hline Histology type & & & & & 0.038 \\
\hline$M C(n=37)$ & 47.8 & $0.0-103.0$ & 51.1 & 48.1 & \\
\hline $\operatorname{SRCC}(n=248)$ & 20.8 & $16.5-25.0$ & 36.9 & 26.0 & \\
\hline $\operatorname{PDC}(n=549)$ & 22.3 & $19.5-25.1$ & 34.9 & 26.1 & \\
\hline Resection margins & & & & & $<0.0001$ \\
\hline $\mathrm{RO}(n=709)$ & 25.4 & $22.4-28.3$ & 39.8 & 30.1 & \\
\hline $\mathrm{R} 1(n=125)$ & 15.8 & $12.7-18.9$ & 15.3 & 8.6 & \\
\hline Lymphatic invasion & & & & & 0.006 \\
\hline No $(n=125)$ & 33.1 & $23.4-42.8$ & 45.6 & 36.0 & \\
\hline Yes $(n=698)$ & 21.5 & $19.5-23.6$ & 34.1 & 25.0 & \\
\hline Vascular invasion & & & & & 0.024 \\
\hline No $(n=635)$ & 24.3 & $21.7-26.9$ & 37.2 & 28.1 & \\
\hline Yes $(n=185)$ & 18.5 & $14.7-22.2$ & 31.7 & 23.2 & \\
\hline Perineural invasion & & & & & $<0.0001$ \\
\hline No $(n=234)$ & 31.4 & $19.1-43.8$ & 46.9 & 40.4 & \\
\hline
\end{tabular}


Table 3 Univariate analysis of prognostic factors for stage III undifferentiated gastric adenocarcinoma (Continued)

\begin{tabular}{|c|c|c|c|c|c|}
\hline Yes $(n=582)$ & 20.8 & $18.7-22.9$ & 31.2 & 21.0 & \\
\hline Chemotherapy & & & & & $<0.001$ \\
\hline No $(n=179)$ & 16.0 & $11.3-20.6$ & 29.1 & 20.3 & \\
\hline Yes $(n=655)$ & 24.5 & $22.0-27.0$ & 38.1 & 28.7 & \\
\hline
\end{tabular}

$C l$ confidence interval, $L N$ ratios, ratios of metastatic to examined lymph nodes, $M C$ mucinous carcinoma, $P D C$ poorly differentiated carcinoma, SRCC signet ring cell carcinoma

Although studies have reported the distinct clinicopathological features of MC compared with non-MC, the results remain inconsistent. Kawamura et al. indicated that the patients with $\mathrm{MC}$ were younger than the non-MC patients [11]. Yin et al. suggested that age had no relationship with $\mathrm{MC}$ and non-MC and $\mathrm{MC}$ was associated with a larger tumor size than non-MC [6]. Other studies found that there was no difference in the tumor size between patients with MC and non-MC [7, 12]. Kunisaki et al. also noted that compared with nonMC, MC had deeper invasion and more lymph node metastasis [7]. In addition, more advanced stages were identified in $\mathrm{MC}$ at the time of diagnosis compared with non-MC $[6,7,10,11,13]$. In this study, we only included stage I-III resected undifferentiated GC and

Table 4 Multivariate analysis of prognostic factors for stage III undifferentiated gastric adenocarcinoma

\begin{tabular}{|c|c|c|c|c|}
\hline \multirow[t]{2}{*}{ Factors } & \multirow[t]{2}{*}{ Hazard ratio (HR) } & \multicolumn{2}{|c|}{$95 \% \mathrm{Cl}$ for $\mathrm{HR}$} & \multirow[t]{2}{*}{$P$ value } \\
\hline & & Lower & Upper & \\
\hline \multicolumn{5}{|c|}{ Type of gastrectomy } \\
\hline Total/subtotal & 1.345 & 1.130 & 1.602 & 0.001 \\
\hline \multicolumn{5}{|l|}{ Tumor size (cm) } \\
\hline$>5 / \leq 5$ & 1.251 & 1.049 & 1.492 & 0.013 \\
\hline \multicolumn{5}{|l|}{ LN ratio } \\
\hline$>0.34 / \leq 0.34$ & 2.262 & 1.892 & 2.704 & $<0.0001$ \\
\hline \multicolumn{5}{|l|}{ Resection margins } \\
\hline $\mathrm{R} 1 / \mathrm{R} 0$ & 1.538 & 1.238 & 1.911 & $<0.001$ \\
\hline \multicolumn{5}{|l|}{ Histology type } \\
\hline $\mathrm{PDC} / \mathrm{MC}$ & 1.594 & 1.012 & 2.510 & 0.044 \\
\hline SRCC/MC & 1.518 & 0.949 & 2.429 & 0.081 \\
\hline \multicolumn{5}{|c|}{ Lymphatic invasion } \\
\hline Yes/no & 1.045 & 0.813 & 1.343 & 0.732 \\
\hline \multicolumn{5}{|l|}{ Vascular invasion } \\
\hline Yes/no & 0.980 & 0.800 & 1.201 & 0.845 \\
\hline \multicolumn{5}{|c|}{ Perineural invasion } \\
\hline Yes/no & 1.335 & 1.095 & 1.627 & 0.004 \\
\hline \multicolumn{5}{|l|}{ Chemotherapy } \\
\hline No/yes & 1.381 & 1.125 & 1.694 & 0.002 \\
\hline
\end{tabular}

$\mathrm{Cl}$ confidence interval, $L N$ ratios, ratios of metastatic to examined lymph nodes, $M C$ mucinous carcinoma, PDC poorly differentiated carcinoma, SRCC signet ring cell carcinoma compared the clinicopathological characteristics of MC with SRCC or PDCC. Significant differences were noted in age; sex; size; depth of tumor invasion; nodal involvement; disease stage; and presence of lymphatic invasion, vascular invasion, and perineural invasion among patients with MC, SRCC, and PDC. In the subgroup analysis of stage III disease, our results showed that older patients, larger tumor size, and higher percentages of perineural invasion were found in those with MC histology compared with SRCC or PDC subtypes; SRCC and PDC had female and male predominance, respectively.

The prognosis of patients with undifferentiated GC compared with other histology is still controversial. Our previous studies have shown that early GC patients with SRCC had more favorable survival than those with nonSRCC; however, advanced SRCC resulted in significantly worse survival than non-SRCC [14]. Interestingly, Kwon et al. found that survival in early GC patients exhibited no difference between histological types; advanced GC patients with SRCC had a worse prognosis than those with other histological types [15]. Furthermore, Shim et al. reported that SRCC is not an independent predictor of poor prognosis after curative resection for GC [16]. Park et al. indicated that histological type was not statistically associated with survival in stage I, II, or III patients in stage-stratified analysis [5]. Similarly, the prognosis

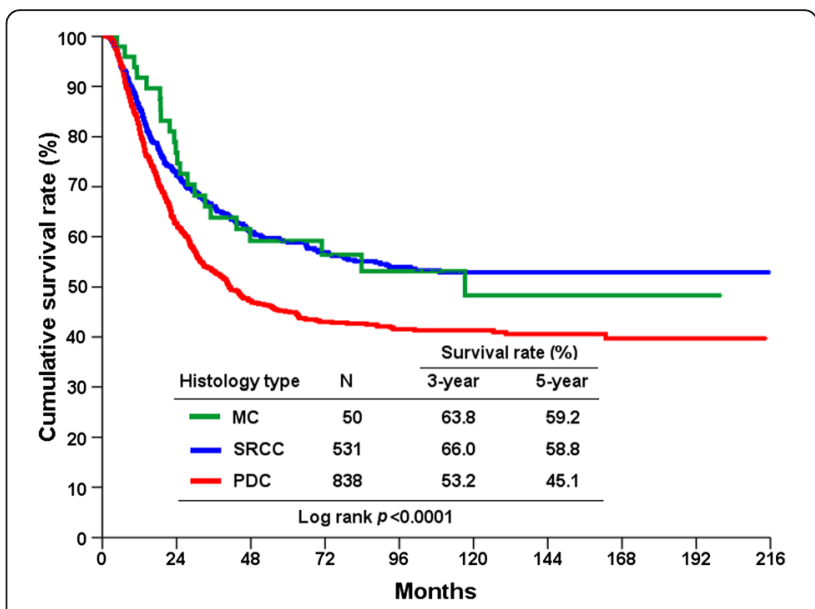

Fig. 1 Cumulative overall survival (OS) rates in stage I-III gastric cancer according to histology type 


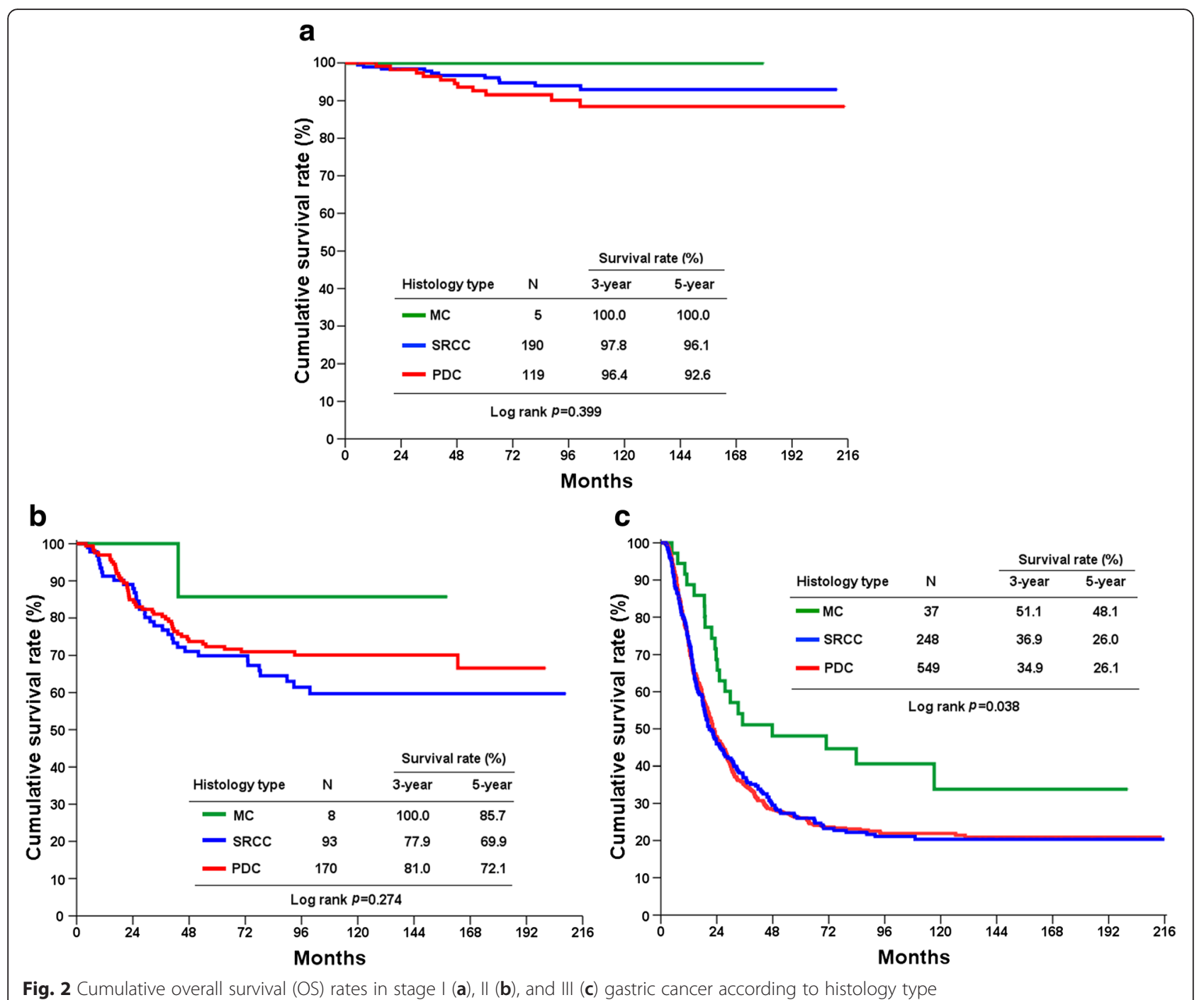

of MC did not differ from non-MC for each stage [6]. In contrast, Fan et al. reported that stage I and II MC patients had a worse 5-year OS than those with SRCC $(P=0.012)$; a difference in 5-year OS was not evident between stage III SRCC and MC groups [17]. In the present study, we examined the outcomes of undifferentiated GC patients undergoing curative intent surgery. Our results, based on stage-stratified analysis, indicated that stage III GC patients with $\mathrm{MC}$ had a better prognosis than those with PDC or SRCC (Fig. 2c; $P=0.038$ ); the difference in OS was not evident in stage I or II patients (Fig. 2a, b). Importantly, MC is an independent prognostic factor in multivariate analysis in stage III disease (PDC vs. MC; $\mathrm{HR}=1.594 ; P=0.044$; Table 4 ), which is different from previous reports [9].

Although stage III patients with MC had an older age and larger tumor size than SRCC or PDC patients, less perineural invasion was identified in $\mathrm{MC}$, which might in part explain the favorable outcome of $\mathrm{MC}$ over other undifferentiated subtypes in the current study. In this regard, Deng et al., using meta-analysis methodology, indicated that perineural invasion is an independent poor prognostic factor in radically resected GC [18]. In line with their findings, our results also showed that perineural invasion is an independent predictor for worse survival in stage III undifferentiated GC in multivariate analysis.

Our results showed that $\mathrm{MC}$ had higher percentages of stage III disease compared with SRCC or PDC. In this regard, previous studies suggested that $\mathrm{MC}$ is believed to arise initially as a typical adenocarcinoma that becomes mucinous as the tumor progresses [12]. Furthermore, the intra-luminal secretion of mucin decreases and the deposit of mucin increases, resulting in intra-luminal accumulation when the tumor invades the gastric wall [19]. Other researchers have noted that MC over-expressed mucin 2 and oligomeric mucus/gel-forming proteins compared with non-MC [10]. In addition, Choi et al. showed that MC presented statistically lower levels of $\beta$-catenin 
and a more advanced stage than non-MC [13]. Nonetheless, more studies are needed to clarify the biological behavior and histogenesis of MC.

\section{Conclusions}

$\mathrm{MC}$ is a rare type of GC. Our results indicated that stage I-III GC with a mucinous subtype presented with different clinicopathological features (older age and larger tumor size) and a different prognosis than SRCC and PDC subtypes. Patients with $\mathrm{MC}$ are more frequently diagnosed with stage III disease compared with other undifferentiated subtypes. There was no difference in survival for stages I or II among MC, SRCC, and PDC. Stage III gastric MC had significantly better survival than SRCC or PDC.

\section{Abbreviations}

GC: gastric adenocarcinoma; MC: mucinous carcinoma; OS: overall survival; PDC: poorly differentiated carcinoma; SRCC: signet ring cell carcinoma.

\section{Competing interests}

The authors declare that they have no competing interests.

\section{Authors' contributions}

HJT contributed to the study design and analysis, management of patients, and drafting and revision of the manuscript. WCW participated in the data collection and study analysis. LPH, CTH, LCJ, and YTS were assigned to the management of patients. WRC participated in the pathological review of the surgical specimen. CKC contributed to the study analysis. All authors read and approved the final manuscript.

\section{Acknowledgements}

The authors thank Shu-Fang Huang for updating the database, for performing the data analysis, and for her assistance in the preparation of the figures. This work was partly supported by the Chang Gung Medical Research Program, Taiwan (CMRPG3C0601, CMRPG3C0602, and CORPG3E0151).

\section{Author details}

'Department of General Surgery, Chang Gung Memorial Hospital at Linkou, Chang Gung University College of Medicine, 5, Fushing Street, Kweishan District, Taoyuan City 333, Taiwan. ${ }^{2}$ Department of Gastroenterology, Chang Gung Memorial Hospital at Linkou, Chang Gung University College of Medicine, Taoyuan, Taiwan. ${ }^{3}$ Department of Pathology, Chang Gung Memorial Hospital at Linkou, Chang Gung University College of Medicine, Taoyuan, Taiwan. ${ }^{4}$ Department of Surgery, Chang Gung Memorial Hospital at Keelung, Chang Gung University College of Medicine, Taoyuan, Taiwan.

Received: 8 December 2015 Accepted: 21 April 2016

Published online: 26 April 2016

\section{References}

1. Ferlay J, Soerjomataram I, Dikshit R, Eser S, Mathers C, Rebelo M, et al. Cancer incidence and mortality worldwide: sources, methods and major patterns in GLOBOCAN 2012. Int J Cancer. 2015;136:E359-86.

2. Hsu JT, Liu MS, Wang F, Chang CJ, Hwang TL, Jan YY, et al. Standard radical gastrectomy in octogenarians and nonagenarians with gastric cancer: are short-term surgical results and long-term survival substantial? J Gastrointest Surg. 2012;16:728-37.

3. Wang F, Chang YC, Chen TH, Hsu JT, Kuo CJ, Lin CJ, et al. Prognostic significance of splenectomy for gastric cancer patients undergoing total gastrectomy: a retrospective cohort study. Int J Surg. 2014;12:557-65.

4. Japanese Gastric Cancer Association. Japanese classification of gastric carcinoma: 3rd English edition. Gastric Cancer. 2011;14:101-12.

5. Park JM, Jang YJ, Kim JH, Park SS, Park SH, Kim SJ, et al. Gastric cancer histology: clinicopathologic characteristics and prognostic value. J Surg Oncol. 2008;98:520-5.
6. Yin C, Li D, Sun Z, Zhang T, Xu Y, Wang Z, et al. Clinicopathologic features and prognosis analysis of mucinous gastric carcinoma. Med Oncol. 2012;29: 864-70.

7. Kunisaki C, Akiyama H, Nomura M, Matsuda G, Otsuka Y, Ono HA, et al. Clinicopathologic characteristics and surgical outcomes of mucinous gastric carcinoma. Ann Surg Oncol. 2006;13:836-42

8. Cheng CT, Tsai CY, Hsu JT, Vinayak R, Liu KH, Yeh CN, et al. Aggressive surgical approach for patients with T4 gastric carcinoma: promise or myth? Ann Surg Oncol. 2011;18:1606-14.

9. Edge SB, Byrd DR, Compton CC, Fritz AG, Greene FL, Trotti A. American Joint Committee on Cancer: AJCC cancer staging manual. 7th ed. New York: Springer; 2009.

10. Choi JS, Kim MA, Lee HE, Lee HS, Kim WH. Mucinous gastric carcinomas: clinicopathologic and molecular analyses. Cancer. 2009;115:3581-90.

11. Kawamura H, Kondo Y, Osawa S, Nisida Y, Okada K, Isizu H, et al. A clinicopathologic study of mucinous adenocarcinoma of the stomach. Gastric Cancer. 2001:4:83-6.

12. Lim SW, Kim DY, Kim YJ, Kim SK. Clinicopathologic features of mucinous gastric carcinoma. Dig Surg. 2002;19:286-90.

13. Choi MG, Sung CO, Noh JH, Kim KM, Sohn TS, Kim S, et al. Mucinous gastric cancer presents with more advanced tumor stage and weaker $\beta$-catenin expression than nonmucinous cancer. Ann Surg Oncol. 2010;17:3053-8.

14. Chiu CT, Kuo CJ, Yeh TS, Hsu JT, Liu KH, Yeh CN, et al. Signet ring cell gastric cancer. Dig Dis Sci. 2011;56:1749-56.

15. Kwon KJ, Shim KN, Song EM, Choi JY, Kim SE, Jung HK, et al. Clinicopathological characteristics and prognosis of signet ring cell carcinoma of the stomach. Gastric Cancer. 2014;17:43-53.

16. Shim JH, Song KY, Kim HH, Han SU, Kim MC, Hyung WJ, et al. Signet ring cell histology is not an independent predictor of poor prognosis after curative resection for gastric cancer: a propensity analysis by the KLASS Group. Medicine. 2014;93:e136.

17. Fang WL, Wu CW, Lo SS, Chen JH, Hsieh MC, Shen KH, et al. Mucin-producing gastric cancer: clinicopathological difference between signet ring cell carcinoma and mucinous carcinoma. Hepatogastroenterology. 2009;56:1227-31.

18. Deng J, You Q, Gao Y, Yu Q, Zhao P, Zheng Y, et al. Prognostic value of perineural invasion in gastric cancer: a systematic review and meta-analysis. PLoS One. 2014:9:e88907.

19. Ma J, De Boer WG, Nayman J. Intestinal mucinous substances in gastric intestinal metaplasia and carcinoma studied by immunofluorescence. Cancer. 1982:49:1664-7.
Submit your next manuscript to BioMed Central and we will help you at every step:

- We accept pre-submission inquiries

- Our selector tool helps you to find the most relevant journal

- We provide round the clock customer support

- Convenient online submission

- Thorough peer review

- Inclusion in PubMed and all major indexing services

- Maximum visibility for your research

Submit your manuscript at www.biomedcentral.com/submit
) BioMed Central 